\title{
Thrombocyte Differentiation
}

National Cancer Institute

\section{Source}

National Cancer Institute. Thrombocyte Differentiation. NCI Thesaurus. Code C96834.

A biological process that refers to the maturation of thrombocytes. 